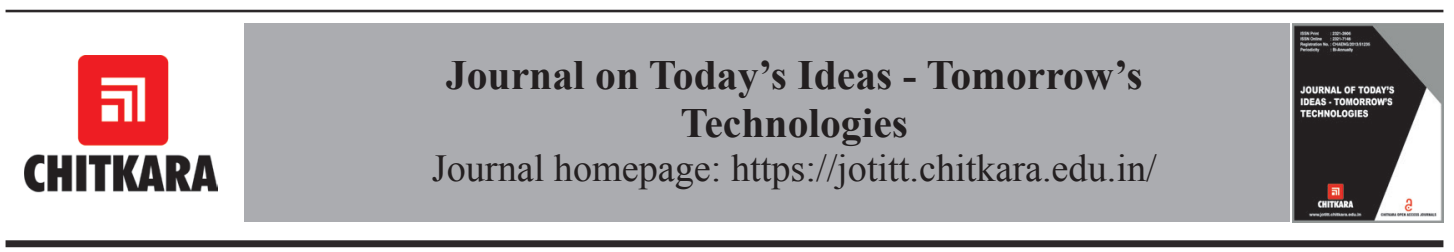

\title{
Techno-Aide Google Classroom for Learning English: Prospects \& Challenges
}

\author{
Md. Sadequle Islam ${ }^{*}$, Syeda Afsana Ferdousi ${ }^{2}$ \\ ${ }^{\prime}$ Faculty of Social Sciences, University of Chittagong, Bangladesh. \\ ${ }^{2} \mathrm{Head}$, Department of English, University of Information Technology \& Sciences, Bangladesh. \\ Email: sadequle.eng@cu.ac.bd*
}

\section{ARTICLE INFORMATION}

Received: April 1, 2019

Revised: August 14, 2019

Accepted: September 20, 2019

Published online: December 30, 2019

Keywords:

Google classroom, technology, learners, teachers, perception, English learning

\begin{abstract}
Google Classroom is a technology aided online learning tool developed by Google which enables both the teachers and learners to fit into beyond the classroom' learning in an innovative way. This research paper tries to shed light on the prospects and challenges of using Google classroom for learning English at the tertiary level education in Bangladesh. For finding out the prospects and challenges, both English language learners' and teachers' perception on the ground of the four language skills- Listening, reading, Writing and Speaking have been studied. The research has been conducted following the quantitative method. An electronic survey was distributed among the students and teachers using Google Form for collecting and comparing responses. The prospect includes how Bangladeshi university students and teachers sense and experience this online tool to stay in touch, as well as develop and manage their work to learn English efficiently. Alongside the common challenges faced by the users (both learners and teachers) this research tries to trace out some technical shortcomings of Google classroom that can be eradicated by Google to turn Google classroom into more user-friendly platform for learning.
\end{abstract}

\section{Introduction}

The method, approach and ways of teaching and learning have been changed radically over the past few years. Islam [1] pointed out that teaching and learning is no more confined within the chalk and talk method. Nowadays teachers are expected to facilitate better learning environment both inside and outside the classroom which may also be termed as "beyond the classroom" learning [2]. This beyond the classroom learning facilitates personalized, competency based and student centred environment. In order to provide such an environment, the first and foremost challenge is the growing dependence 
on technology and which has become central to the lives of the younger generation [3]. Use of technology for teaching and learning English is not a new trend. Computerassisted language learning has commenced back in the 1960s. In this age of smartphones, use of smart-mobile-phones is very common with students and mobile phone is able to do rather more than the laptops or computers. As the world is surrounded by technology and the internet, youths today are part of a digital generation where they are using mobile phones, computers, tablets and e-readers on a daily basis. Since the gadgets are increasing day by day, it is leading to the technology addiction among children. Young people even toddlers are spending more and more time with digital technology. Some students are so fond of the use of gadgets that they can't control themselves to use it even inside the classroom, which in many ways distracts both the teachers and learners. Parents and teachers are very much anxious about this touch screen generation. Since the application of mobile technology is escalating, why not offer learners the option to learn anywhere, anytime and at their own convenience with the help of their electronic devices? Considering this matter, in 2014, Google planned for introducing a technology based learning platform through which these gadget loving young generation can be taught by using their much loved gadget where they usually spend most of the time of their day and night. And so did it happen; Google classroom transformed this problem of young generation's techno-dependency into a solution. It has become more than an online learning platform itself as a positive instance of technology, since it enhances personalized, anywhere \& anytime learning which resembles learning beyond the classroom. Since Google classroom is also an app-based and web-friendly online learning platform, number of researchers tried to trace out Google classroom's prospects and challenges in terms of teaching and learning various subjects of different disciplines including science, social studies, business studies and so on. But not any considerable research work has been done in terms of teaching and learning English through Google classroom. Considering this as a research gap, through this paper, the researcher tried to find out tertiary level learners' and teachers' perception towards the prospects and challenges of using Google classroom in terms of learning English. The research has been conducted among the students of Daffodil International University as this university is the first in Bangladesh to make the use of Google classroom compulsory for teaching and learning in each and every department. This study aims to find out certain identifiers which trace out learners personal experience of the using technology, most specifically Google classroom, for learning English. Such identification will help both the English language teachers and learners those who use Google classroom by providing a read of what potential obstacles ought to be relieved before using it. Technical barriers faced by the learners (as found in this research) while using Google classroom will give the concerned app-builders for possible update or improvement of the application.

\section{Literature Review}

A well known concept in the studies of technology use in language learning is computer assisted language learning (CALL). The term was first used in the 1960 s and originates from the United States [4]. Both second language acquisition theories and trends in language pedagogy have modified the meaning of the term ever since (Davies, Otto and Rüschoff, 2012). Apart from that, the revolutions in technology have shaped 
the term CALL. The use of portable digital devices, such as smart phones, laptops and tabs has become a norm in people's lives; CALL has become more recognized as an innovative area of scholarship [4]. Since various applications are more and more integrated into language teaching, the study of Computer Assisted Language learning has become more familiar and thus there are constantly new facets to study [5].

Today's youths, who are often called as the 'Net Generation', grow up with technology. A large portion of them have never known existence without the Internet. They like to spend their whole day utilizing PCs, mobile phones, and other advanced media and have coordinated innovation into nearly all that they do. Clearly innovation is an essential piece of their lives. It has been noticed that, in educational institutions, there are students in the classroom who may, at first glance in any event, have all the earmarks of being more carefully skilled than their teachers are. To make them more engaged in learning, there has been augmented importance on the incorporation of technology into the classrooms [6]. Though teaching and learning are the indispensable features within a classroom, to support students' development and nourishment technology is significant to incorporate into the classroom [7].

In foreign language teaching, technological devices have been used for decades. Computers were introduced to foreign language learning field already in 1960 s [8] and the developments in technology have brought many new devices into teaching ever since. Variations have already been introduced and besides computers, mobile devices like smart phones and tablets have also become a part of teaching.

Bebell \& Kay [9] said that students utilize laptop computers or hand held tablets daily as a part of the class curriculum, and many of these computing devices go home with the students at the end of the school day. In Bangladesh the scenario is almost same. Students like to use gadgets both in and outside the classroom. So, if students are allowed to provide class materials through these devices by which they can both learn within and beyond the classroom it would be very helpful for both the teachers and learners. Keeping this in mind, Google has introduced its learning app Google classroom in 2014. According to Wikipedia, Google Classroom is an online learning platform which promotes blended learning both within and beyond the classroom.

\section{Google Classroom}

Google classroom is an online teaching and learning aid that helps to simplify the process of taking and grading exams and assignments in a paperless way. Apart from these, this free application helps both the teachers and students to communicate well in order to engage beyond the classroom teaching and learning. As a feature of Google App, it is the only application that Google has designed exclusively for teachers and students. Google classroom can either be used as an app by installing it in the smart phones or it can be used in the computer as the desktop version. Iftakhar, S. [10] stated, "Google Classroom is meant to help teachers manage the creation and collection of student assignments in a paperless environment, basically leveraging the framework of Google Docs, Drive and other apps. Google classroom allows teachers to spend more time with their students and less time on the paperwork; which is now even better" [10].

\subsection{How does it work}

Google Classroom presents more professional and authentic technology to use in learning environment. One can create 
and join in a Google classroom if he/ she has a Gmail account. Creating Google class is very easy task and after creating the class, the teacher will provide class code to the learners. By using the code learners can directly incorporate them in the specific teacher's classroom. A teacher can create announcement, assignment, take exam or even can send e-mails to the students. Teacher can contact with the guardians through e-mail (If their e-mail addresses are provided) just by a single click. Unlike Google's regular services, Google Classroom does not allow any advertisements in its interface and user data is not used or scanned for advertising purposes [11].

Google has Google Doc, Dive, Calendar and form those can be integrated with Google classroom for more interactive learning and teaching. Google Calendar can be used for due dates and events outside the classroom, and other important "chronological data."Google Forms can be used for self grading assessment. Learners could utilize the results to create new learning goals. In the Google form, classroom groups can be created based on interest, reading level, readiness or other factors for teaching and learning and also for group presentation and assignments. The students in the school or college usually maintain a diary that they use to record information about lectures or class materials. They take it home and additionally use it at school. A form can be created using Google by the learners which can play the same function of a reading diary to enter information about their reading. Google Doc is used to share documents and work collaboratively on writing projects. The teacher can even invite another Google user into class to do a guest lecture through Video Chat.

In Google Classroom, there is a timeline that appears by default when someone login to his/her class. This stream can be used to collect student opinions by creating discussion topics. Since the platform depends on Google Drive for transferring archives and assignments, it is additionally encouraged to actualize the e-portfolio strategy. Both the learners and teachers can make documents and folders that can be shared between one another. [12] If the learners work in groups, they can create their own shared folder. This is how the group's' work will be accessible to every one of the group, even if one or more are absent. As everything occurs in the cloud, everything should be possible offbeat.

\subsection{Use of google classroom for teaching english}

Learning any language is about learning the four basic skills- Listening, reading, writing \& speaking. English learning is not an exception to it. So, for learning these four skills of English, Google classroom can be used as a medium in a very innovative way. Islam [1], mentioned possible tasks and activities and those can be incorporated in the Google classroom for learning these four skills. These are:

\subsubsection{Writing}

For practising English writing skill, students can be asked to write something on any topic based on their own experience and they are asked to upload those in the assignment section of Google classroom where only the teacher can see and read their write up. After submitting their write up, the teacher can also give feedbacks to the learners. Another way of engaging them for writing through Google classroom is to give them various interesting English videos in the Google classroom including movie clip, reality shows, speeches, documentaries etc and they can be instructed to write their own review on those videos. Students often like these interesting 
videos and enthusiastically they engage in the writing activity.

\subsubsection{Speaking}

First of all, Learners can be given some suggestions on some techniques for becoming a better speaker. Video clips of famous orators or public speakers can also be uploaded for their convenience. Now, they will be asked to make their own video where each will be assigned to talk on any familiar but specific topic. They can also be asked to make English short documentaries/films on interesting and contemporary issues. They can make the documentary/film in groups so that their conversational skill will also be improved.

\subsubsection{Listening}

For listening practice students can be given various listening practice audio along with practise sheet available on the internet. To make listening a bit interesting and to engage them enthusiastically they can be given English songs or interesting movie clips. Considering the learners' level of English proficiency, teachers have to make questions from the lyrics of the song and students can be asked to answer those questions by listening to the songs or movie clips. A quiz can also be arranged in the Google classroom.

\subsubsection{Reading}

There are enormous passages for practising reading. Students can be provided those reading text along with multiple choice or fill in the gaps questions. These will help them to improve reading skill. Apart from that, story books can be assigned to them. After reading the book they have to submit a book review.

So these are some of the tasks associated with the four skills of English which can be incorporated through Google classroom for ensuring a better English learning environment to students.

\section{Research Methods}

\subsection{Research objective}

The objective of the research is to find out the prospects and the challenges faced by the students and teachers in case of using Google classroom to learn English. The prospects include the ways which can be followed in order to learn English more effectively by using Google classroom whereas the challenges include the problems the students and teachers face while using it.

\subsection{Research questions}

There are two research questions on a broad line. These are:

1. What are the prospects of Google classroom in learning English?

2. What are the challenges of Google classroom faced by learners/teachers while using it??

\subsection{Significance of the study}

The result of the study will help both the English language teachers and learners those who use Google classroom by providing a read of what potential obstacles ought to be relieved before using it. Technical barriers faced by the learners (as found in this research) while using Google classroom will give the concerned app-builders for possible update or improvement of the application. Apart from that the teachers can also take a look at the possibilities of using Google classroom from students' perspective which can also be implemented practically to help students be more engaged.

\subsection{Participants}

One hundred (100) students and ten (10) teachers of Daffodil International University, Bangladesh are the participants of this research. Daffodil International University is the first university in Bangladesh to pioneer 
mandatory use of Google classroom for each and every course. The participants were from Department of Pharmacy and Department of Business Administration. These students were from first semester and they had a 03 credit "Basic English" course. In this course the four basic skills of communication are integrated and thus there are activities related to all these four skills some of which are also incorporated and practiced through Google classroom. Among the student participants, 50 were male and 50 were female. That is, the ratio of male-female participant is 50:50. The age range of the student participants is mostly within 18-21 years. And among the teachers 4 were male and 6 were female. It can be mentioned that all of these teachers' use Google classroom as an alternative learning platform for teaching English.

\subsection{Instruments}

An electronic survey was created using Google Forms for collecting and comparing responses. The survey questionnaire was consisted of two sections. The first section of the questionnaire was consisted of 20 prompts to which the learners could rate their agreement or disagreement via Likert scale. All the questions are asked on the basis of the theoretical research in literature review that is their experience of the use of Google classroom in terms of learning four specific skills of English. The last part has two questions based on the participants' personal opinion regarding the use of Google classroom in learning English.

\subsection{Methods of data analysis}

Data found from the questionnaire have been analyzed on the basis of Likert Scale. The participants mentioned some technical issues as "problems of using Google classroom", which are again tested by a Google classroom expert. It has been found that some of those "problems" are not truly technical problem rather they faced those due to their lack of practical knowledge.

\subsection{Limitations}

The study was conducted only among 100 students and 10 teachers of two departments of Daffodil International University. Although, there are total 24 departments in Daffodil International University, due to time constraints it was not possible to take everyone's opinion. So, the number of participants was not huge. Another thing is that it would be better if detailed interview of some of the students could be taken.

\section{Finding \& Discussion}

From the opinion of the students the prospects and the challenges of using Google classroom (G.C.) are sort out and mentioned here:

Benefits of Google classroom (G.C.) for learning English:

82 percent learners said that it can easily be used anytime and anywhere either by mobile, laptop or any other electronic gadgets having internet connection. Learners can share their queries and teachers can give comments thus they can easily participate in open discussion regarding any topic. After the exam, result can be easily and immediately be found; and since there is scope to give feedback to the mistakes, 56 percent learners think that it helps them a lot for correcting their mistakes. From the figure 1, it can be showed that, when the learners were asked about the use of Google classroom for practicing speaking, 46 percent students agreed on the point that video quiz/video speaking test is very much interesting to them. One important finding of this factor is that the students who were feeling shy/reluctant to speak in front of the classroom, they also said that they like 
this video quiz/video speaking test. And by analysing their uploaded video in the Google classroom, surprisingly it has been found that those students did noticeably better in the video speaking test than their performance in front of the classroom. So, at the primary stage, the introvert students can be engaged in speaking through this video speaking test and by doing it gradually when they will get rid of shyness, they will start speaking in front of the class. Another thing is that, majority of the students think that for increasing the ability to speak, you tube links of various videos attached in the Google classroom help them a lot. of the further modification of the feature of Google classroom. They said that sometimes, the uploaded audio files do not work out properly and in the middle of upload, if there is some internet problem, one has to start from the very beginning again which is a hassle for the learners.

When the learners are asked about prospect of Google classroom for practising reading skill, 79 percent learners said that uploaded reading passages can be read easily and they can submit the answers to the questions from the passage online; without any trouble. Materials for reading exercises are also easy to read from the

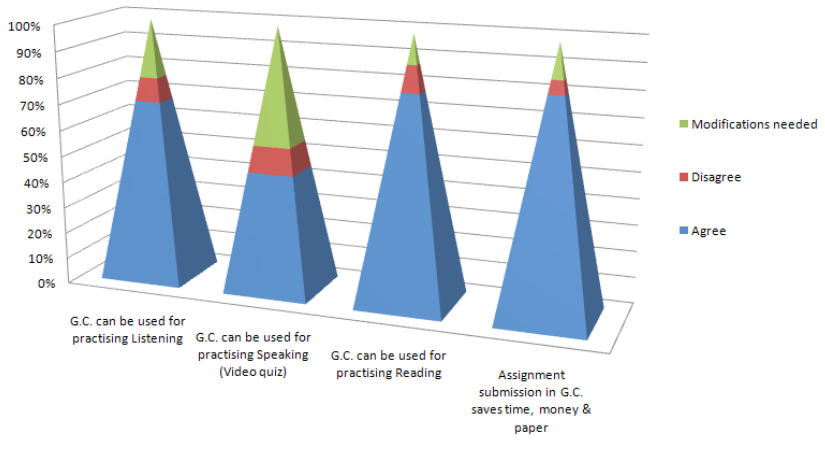

Figure 1: Learners' perception

Fig. 1 shows that 69 percent learners agreed on the notion that Google Classroom can be used for practicing Listening. They said that listening practise in Google classroom is easy, convenient, hassle free and does not need any language lab. A mobile phone with a headphone can be enough to function as a lab. For practising listening skill, initially they have been given Songs and 90 percent students said that practising English listening skill by listening to English song is really interesting and engaging. A very few students showed their indifference for conversational listening audios like Cambridge listening practice test and 22 percent gave their opinion in favour
Google classroom provided that the internet connection is on. 82 percent students think that it is paperless-eco friendly and there is no fear about losing the uploaded materials. One thing that can be focused here is, a mentionable number of students ( 44 percent) mentioned that modification is needed for using G.C. (Google classroom for practicing speaking). From figure 1, it can be seen that, 82 percent learners opine that submission of any assignment or any writeup in Google classroom saves time, money, paper and most importantly it is hassle free whereas 13 percent said that modification is needed for make it more convenient Since 
various class materials are uploaded in the Google classroom after the class, student gave the statement that they can be able to keep themselves updated regularly about makeup class, exam date and important announcements. In fact it acts as an online notice board for the learner. Even if any student misses the class he will get a soft idea about the class in Google classroom if the class lecture is uploaded by the teacher.

\subsection{Challenges of Google classroom for learning English}

Learners said that Google classroom is not convenient for interacting with other fellow learners privately. Learners' can't communicate with each other by sending private message/group message. If someone wants to say something to his/her fellow learner he/she has to write a public comment

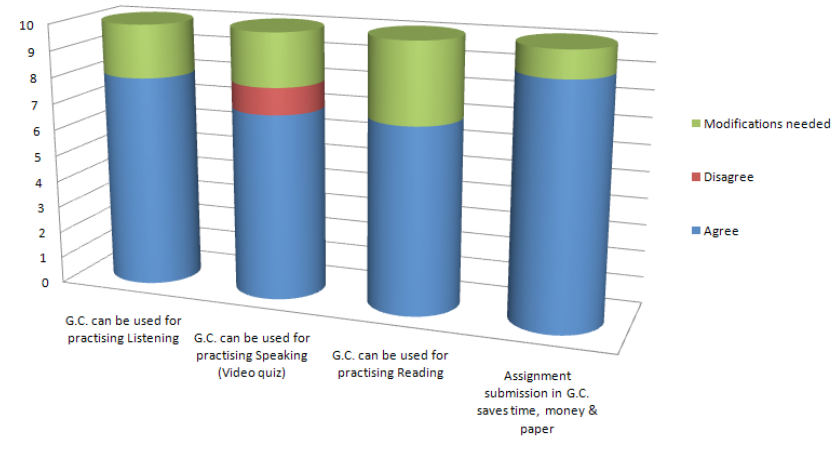

Figure 2: Teachers' perception

Fig. 2 shows the response of the teachers. Here for practising listening 80 percent, for practising speaking and reading 70 percent and for writing/submission of assignment 82 percent teachers totally agreed on the positive role of Google Classroom (G.C). Only 10 percent teachers disagreed on the positive role of Google classroom for practising speaking and he has mentioned that he witnessed/experienced some students' problems in terms of uploading video assignments. For all the four skills, a mentionable number of teachers opined that modifications are needed to make Google classroom a better one. From the figure 2, it can be seen that 30 percent teachers said that some G.C's feature need to be are modified for facilitating smoother reading practise. on any public announcement/ post or directly create a public post on the classroom by tagging that very specific learner which will be viewed by every learner and teacher as well. Participants think that this way of communication with the fellow learner is very time consuming and in some cases hinders privacy. They also think that by following this way, discussion of any specific academic problem is tiresome.

Almost same is the case for learnerteacher communication. Only private comment option is possible with the teachers below the "assignment" post i.e. only if the teacher gives any assignment, the students will be able to send private message (private comment basically) to their teacher. This issue is considered as a terrible problem by 
71 percent of the participants. They think that since there is no "one to one" private message option with the teacher in Google classroom, for every individual problem, they have to either send mail or give phone call to their teacher. 65 percent learners said that, due to the absence of any "messaging" option at Google classroom they faced tremendous problem for asking queries, questions or clarifications of their problems to their teachers. 62 percent teachers also opine that they also cannot communicate with their students personally through messaging. It is only possible through e-mail and students are not always available on e-mail.

71 percent students stated that random and spontaneous face-to-face interactions through questions or described opinions are required in presenting the full scope of learning English. They added that a teacher often understands the problem of the students by eye-contact which is not possible by Google classroom. They also said that in the Google classroom, the teacher is generally capable of interacting with only one student at a time and it is from behind a mobile or computer screen where the teachers can't get the pulse of the students accordingly hence cannot give the maximum effort to clarify any point.

67 percent of the participating students think that slides provided at Google classroom are not solely enough for learning and it can be adjuncts rather than alternative to conventional classroom most specifically in terms of learning English. By analysing the comments of the learners it has been traced out that these 67 percent students think that if there is any live classroom facility, it will be much more convenient for them. They also mentioned the necessity of teacher-student interaction through the implementation of live lecturing, video chatting and messaging with multiple students and on this point 30 percent teachers expressed their stand quite similar to these students. These teachers are also in favour of live classroom facility.

88 percent students said that, as an App, Google classroom cannot be used without internet connection even there is no option to view/read the files offline from the app. Two of the students mentioned that, since internet in Bangladesh is quite costly i,e not free and when they are at the university they often get the wifi connection but when they are outside the university premise it is quite usual that they always do not have balance/ internet package at their mobile phone, In such situation they are unable to get timely updates from the teacher regarding any assignment/class.

A remarkable challenge of the use of Google classroom has been noted from 51 percent of the participants. They said that when they use Google classroom on mobile phone/electronic devices, their parents think that they are wasting time by using internet. In the context of Bangladesh, most of the parents do not have the idea of Google classroom and they sometimes scold them for using mobile phone during their study time at their reading table.

68 percent of the students said that when they have to upload the video assignments or English speaking test in the Google classroom, they terribly face the predicament of low speed of the internet connection. Sometimes they cannot upload the whole file and in the mid of it, their internet becomes disconnected. As a result of that their assignments are shown undone and they have to again start the uploading from the beginning. 50 percent teachers also mentioned quite a similar challenge. They said that they faced problems in terms of uploading audio and video files.

The stream / timeline of the Google classroom cannot get auto refreshed/auto updated. In order to get the new post, the 
user needs to reload/refresh the page continuously. In this circumstance, when the students have to appear any test (most specifically English reading test), 65 percent of them face problems. For each question posted by the teacher they have to reload the page and wait. Students only having Google account/ gmail account can have access to Google classroom. In any case, if the teacher opens the class with the e-mail ID provided by the university, then the students should also have the same institutional email ID to join that very specific teacher's class. In this case, 59 percent students think that this is not always convenient for them since they sometimes forget their email password.

10 percent respondents claimed a very serious challenge of Google classroom. They said that taking exam (most specifically listening and reading tests) in the Google classroom paves the way for dishonesty. They mentioned that when teachers take any test in the Google classroom, students sit together at their dormitories or they communicate over mobile phone in conference calls, discuss with each other and answer the questions by adopting unfair means. Another student said that if one of the students write assignment and share the document with his/her friend's group, there are probabilities that whole group would exploit that very document for submission or make slight changes and submit the same. Almost every teacher (90 percent) said that taking tests/ exams through Google classroom lacks the transparency and most of them for this reason avoid Google classroom for taking any quiz or test. So these loop holes of Google classroom allow the students to cheating.

\section{Conclusion}

This research has an aim to unearth teachers' and learners' perceptions (specifically the pros \& the cons) of the techno aide Google
Classroom for learning English. It has been found that a number of problems have been brought up by both the teachers and learners which are better to be addressed by both the teachers and the Google technical team. For instance, the most frequent challenge faced by the students is their lack of proper technological knowledge about Google classroom. A huge number of students said that they started using Google classroom without any proper training from the experts; even some of the learners don't know what the basic functions of Google classroom are. Only the concerned teacher taught them how to join a class, how to post about a query and how to submit assignment. Most of the time while submitting assignment they faced unwanted technological issues. So, learners' suggested that proper training on the use of Google classroom can enhance their performance and it may result a successful learning. Again some teachers also said that they are not that much efficient in terms of using Google classroom. They are no given enough training on the use of it. If the teachers are not well trained, how is it possible for him/her to train his/her students? Learners also mentioned some technological barriers they faced while using Google classroom for example, barrier of using Google classroom having e-mail address with different domain, cheating option for learner, lack of private messaging option, and problem with the autoupdate of homepage (stream). So these issues can be addressed by the Google technical team and possible improvement/modification can be done by the technical support of Google. Besides, the findings showed some pros which can be very helpful for both the English language learners and teachers for making Google classroom more successful and innovative learning platform. After all trough this research paper, the best possible 
techniques for learning listening, reading, writing and speaking are traced out which can make English language learning through Google classroom a success. Technology is not stagnant rather it is always changing. The truth is that technology will always require upgrades; a new feature comes to be replaced by the newer one. So the future work of this research will study the perception of both the learners and teachers in terms of using Google classroom for teaching English after two years and thus it will try to do a comparative analysis of the viewpoint of both the teachers and learners within a time gap of two years.

\section{Funding}

The paper is a part of the project funded by Research and Publication Cell, University of Chittagong, Bangladesh.

\section{References}

[1] M. S. Islam, "Bangladeshi university students' Perception on using google classroom for teaching english," International Journal of Psycho-Educational Sciences, vol. 8, no. 2, pp. 57-65, 2019.

[2] S. Patrick, and C. Sturgis, "Maximizing competency education and blended learning: Insights from experts," 2015. [Online]. Available : https://files.eric. ed.gov/fulltext/ED557755.pdf [Accessed December 12, 2018]

[3] S. Curtis, "How technology is changing childhood," The Telegraph, pp. 6, 2013. [Online]. Available: https:// www.telegraph.co.uk/technology/ news / 10529785 / How-technology-is-changing-childhood.html [Accessed December 06, 2018]

[4] M. Thomas, H. Reinders, and M. Warschauer, "Contemporary computer-assisted language learning: The role of digital media and incremental change,"
In Contemporary computer-assisted language learning, London: Bloomsbury Publishing, 2012, pp. 21-31.

[5] M. Warschauer, "Computer-assisted language learning: An introduction," Multimedia Language Teaching, S. Fotos, Eds. Tokyo: Logos International, 1996, pp. 3-20.

[6] Y.-J. An, and C. Reigeluth, "Creating technology-enhanced, learner-centered classrooms: K-12 teachers' beliefs, perceptions, barriers, and support needs," Journal of Digital Learning in Teacher Education, vol. 28, no. 2, pp. 54-62, 2011.

[7] K. N. Nemeth, and F.S. Simon, "Using technology as a teaching tool for dual language learners in preschool through grade 3," National Association for the Education of Toung Children, vol. 68, no. 1, pp. 48-52, 2013.

[8] R. Mahrooqi, and S. Troudi, "Using technology in foreign language teaching," Cambridge: Scholars Publishing, 2014.

[9] D. Bebell, and R. Kay, "One to one computing: A summary of the quantitative results of the Berkshire Wireless learning initiative," The Journal of Technology, Learning, and Assessment, vol 9, no. 2, pp. 1-60, 2010.

[10]S. Iftakhar, "Google classroom: What works and how?" Journal of Education and Social Sciences, vol. 3, pp. 12-18, 2016.

[11] "Google Classroom," 2016. [Online]. Available: https://blogs.umass.edu/onlinetools/community-centered-tools/ google-classroom [Accessed November 20, 2018]

[12] A. Keeler, "15 more things you can do with google classroom,” 2014. [Online]. Available: https://alicekeeler. com/2014/09/22/15-more-thingsyou-can-do-with-google-classroom/ [Accessed December 21, 2018] 
Journal on Today's Ideas - Tomorrow's Technologies

Chitkara University, Saraswati Kendra, SCO 160-161, Sector 9-C, Chandigarh, 160009, India CHITKARA UNIVERSITY

Volume -7, Issue-2

December 2019

ISSN 2321-3906

Copyright: [C 2019 Md. Sadequle Islam and Syeda Afsana Ferdousi] This is an Open Access article published in Journal on Today's Ideas - Tomorrow's Technologies by Chitkara University Publications. It is published with a Creative Commons Attribution- CC-BY 4.0 International License. This license permits unrestricted use, distribution, and reproduction in any medium, provided the original author and source are credited. 